\title{
Schädlicher Einfluss der Mercurial-Pasten auf die Zähne.
}

Tal m a beschreibt den schädlichen Einfluss des innerlich gebrauchten Quecksilbers auf die Zahne. Sie erhalten ein dunkles Ansehen, der Bleifarbe verwandt, und als Folge zeigt sich ein Lockerwerden und Ausfallen derselben. - Er führt ferner an, dass unter dem Namen Minéral Succedaneum auch pate d'argent de Taveau und Mastic de Bell genannt, ein Pflaster zur Plombirung vorkomme, welches aus Mercur und Silber bestehe, auch gewöhnlich etwas Kupfer enthalte. Die Verfliichtigung des Quecksilbers, veranlasst durch die Wärme im Munde, bewirkt bald ein Erhärten der Masse in den Zähnen. Áber jene Verflichtigung ist gefährlich und ubt den bekannten nachtheiligen Einfluss aus. Gold und Zinn dagegen wird empfohlen, wenn Caries eintritt. (Gaz. méd. No. 10. 1846. Journ. de Pharm. et de Chim. p. 438.) Witting.

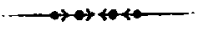

\section{Candirte Pillen.}

In Paris hat man nun auch angefangen, um dem Kranken das Einnehmen der Pillen von üblem Geruch und Geschmack angenehmer zu machen, dieselben mit einer Hülle von arabisohem Gummi für sich, oder in Vermengung mit Elaeosaccharum Citri, oder auch mit Amylum zu versehen.

Dieses Einrollen oder Umhüllen geschieht auf åhnliche Weise wie das Vergolden der Pillen. Nachdem sie nåmlich geformt sind, werden sie in eine sphärische Büchse gelegt, man lässt 1 oder 2 Tropfen oder überhaupt so viel Syrupus simplex darauf fallen, als hinreichend ist, um die Pillen durch kreisformiges Bewegen der Büchse damit schwach und gleichformig zu befeuchten; hierauf fügt man das Gummipulver für sich oder mit Oelaucker vermengt nach und nach in kleinen Antheilen hinzu, und fährt mit der kreisförmigen Bewegung der Büchse so lange fort, bis die Pillen nichts mehr davon aufnehmen; hierauf nimmt man sie aus der Büchse, legt sie auf einen Teller und lässt sie an der Luft etwas abtrocknen; die Pillen sehen dann aus wie überzuckert.

Ein paar beliebte Receptformeln solcher candirten Pillen des Dr. Douvandt sind :

Pilulae ferri carbonici.

Rec. Ferr, sulphuric. pur.

Kali carbonici ana 3 jj

Pulv. rad. rhei " fol. jugland. ana $3 \mathrm{j}$

Mucilag. G. arab. q. s. ut. f. massa, ex qua formentur pilolae No.60, quae, leviter humectatac, pulvere gummi arabici subtilissime cum Elaeosacchar, Citri mixto involvastur. 